\title{
34
}

\section{ITEM as a Catalyst for School Reform}

Discussion chaired by:

Patrick Nolan $^{\mathrm{a}}$, Arthur Tatnall ${ }^{\mathrm{b}}$

${ }^{a}$ Massey University, New Zealand

${ }^{b}$ Victoria University of Technology, Australia

\section{INTRODUCTION}

The topic for discussion, ITEM as a catalyst of school reform, was addressed using a structured workshop technique: (i) initial "brainstorming" by the whole group to establish a modus operandi and agree on objectives and procedures; (ii) heterogeneous task groups to carry out the work; and (iii) reporting back which included discussion and agreement on the form and content of the report.

The brainstorming session identified two broad perspectives within which the participants elected to discuss the topic: (i) a Minimalist perspective; and (ii) a Maximalist perspective. Groups were formed corresponding with this distinction. The task for each group was to produce a report on the topic under five headings:

1. An overall summary;

2. School reform - meaning, focus/scope, task;

3. The meaning of ITEM as catalyst, e.g. stimulus, cause, result;

4. The meaning and scope of ITEM (what it includes/excludes); and

5 . Issues and challenges to be addressed and resolved.

Although Pat Nolan and Arthur Tatnall acted as group leaders and editors, the final report is the collective product of all the group members listed below:

Ben Zion Barta (Israel), Rory Butler (New Zealand), Rosario Berriel (Spain), Helene Dimmitt (Australia), Connie Fulmer (USA), Yaffa Gev (Israel), Rami Hazarchi (Israel), Tsurayuki Kado (Japan), Porya Kalai (Israel),Pat Nolan (New Zealand), Luis Osin (Israel), Javier Osorio (Spain), Jorge Rodriguez (Spain), Israelit Rubinstein (Israel), Ilana Sagi (Israel) Yaacov Sapir (Israel), Arthur Tatnall (Australia), Ray Taylor (USA), Moshe Telem (Israel), Adrie Visscher (Netherlands).

The contents are presented under the two headings of Minimalist and Maximilist, with summary comments given at the end in the conclusion.

\section{MINIMALIST PERSPECTIVE}

The term Minimalist is used to indicate a limitation on the least that it was thought could be meaningfully addressed within the given topic, at least initially. In other words, this group took the view that the domain to which ITEM can be sensibly applied does not encompass all educational topics. 


\section{Overall summary}

The Minimalist group made three summary points. Firstly, ITEM challenges educational professionals (school administrators and teachers alike) and researchers to confront and actively deal with the inevitability of change associated with information technology developments affecting education. Secondly, ITEM is not a panacea for solving the persistent problems and issues of education. Thus, a healthy skepticism is required to properly assess the likely costs and benefits of applying information technology to, and within, education generally and educational management in particular. This point reiterates the counsel of caution made by Dr Gershon Metzger in his opening address. Thirdly, given the complexity of educational institutions, there is a need to know much more about how to make design and implementation strategies work effectively in educational contexts.

\section{School reform}

Within the Minimalist perspective, school reform is taken to mean change for the better (i.e. the task). Reform, thus defined, is sometimes interpreted as improving efficiency and/or effectiveness.

The scope of reform is such that it may occur at any school level or with regard to any school function. It may involve: (i) more efficient and equitable allocation of resources in regard to classes, contact hours, educational materials and the ratio of teachers to pupils; (ii) changing the relationship between teachers, administrators and principals (e.g. away from topdown authoritarian practice to bottom-up collaborative practices), and (iii) changes in classroom processes and teacher-student relationships which may affect traditional teacher role definitions, authority and status.

\section{The meaning of ITEM}

ITEM includes information processing systems and tools to fulfill optimal pre-conditions for the learning and teaching process. The definition excludes the use of information technology in the actual process of delivering learning and teaching. In this sense, ITEM is essentially a means to an end, not an end in itself.

\section{ITEM as a catalyst}

ITEM as a catalyst may, depending on circumstances, serve as a stimulus, a cause and an outcome of an externally imposed decision. For example, a regional educational authority may decree that schools employ information technology to meet accountability requirements. Thus used, however, it may stimulate other uses that meet a school's internal administrative needs.

\section{Issues and challenges}

Given the conservative nature of schools and teachers lack of experience with information technology, overcoming teachers' and school administrators' fear of information technology will be a major challenge, requiring sustained professional development and support programmes into the foreseeable future.

Educational institutions such as schools have characteristics which distinguish them from other kinds of institutions, e.g. a bank or a manufacturing business. A task, not to be underestimated in its complexity, is that of designing ITEM systems with characteristics (and capabilities) which match the organisational, administrative and managerial characteristics of schools.

The society which schools are intended to serve is changing rapidly, and will continue to do so, into the foreseeable future. If schools are to educate students for that society they too must continue to develop and change. Theorising about and developing schools that will meet the educational needs of children in the society of today and tomorrow is a matter of top priority. A challenge is to design ITEM systems that support and enhance the primary objectives of such schools. 


\section{THE MAXIMALIST PERSPECTIVE}

This group took the view that information technology in general, and ITEM (broadly defined), had the potential to produce fundamental changes in all aspects of the school system. For instance, it has the potential to democratise school admininistration by making key information more freely and widly available to all school personnel. It was stressed that the purpose of educational management at any level is to create the conditions necessary for effective teaching and learning. Here too, educational management is seen as a means to an end, and not as an end in itself.

\section{Overall summary}

Information technology is a means which has a huge potential for helping schools manage the process of helping learners reach their individual and interpersonal potentials.

\section{School reform}

School reform is the process of organising all the subsystems of schools such that they are effective with respect to their objectives - more specifically, that they will enhance learning as a social process while not compromising a concern for the individual.

The focus of school reforms is that all learners (including students, teachers, administrators) have a right to maximise their potential, and that maximisation ought to satisfy society's needs. The scope is any educational system and includes all subsystems. ITEM.

The task of school reform is to prepare an infrastructure to achieve the above, including

\section{The meaning of ITEM}

ITEM should be thought of as Information Technology for Educational Management, and includes all those subsystems of schools which will yield to information technology administrative, instructional, student services, etc.

\section{ITEM as catalyst}

The group felt that a more appropriate term than 'catalyst' would be 'means'. The discussion would then hinge around the concept of ITEM as a 'means' of school reform.

\section{Issues and challenges}

There is a need to do further work on the word 'means'. The group felt it understates their intended meaning.

Among 'hardware / software / humanware', the latter is the one that is furthest behind.

Hardware and software capable of achieving the task at hand may not yet exist.

\section{CAVEAT - THE TWO GROUPS}

Conversation in the Maximilist group was limited by the need to accommodate some minimalist participants. A similar accommodation was made in the Minimalist group. This left both groups with a perception that views expressed in this document may be even further apart than they appear on the surface.

\section{Change for the better?}

It was acknowledged that not all change that may be caused by the use of ITEM is change for the better. In one case mentioned, the introduction of ITEM actually frustrated and stifled educational innovation and reform. Hopefully this will not be a common occurrence.

Like the Minimalists, for the purposes of this discussion, school reform was taken to refer only to beneficial change. 


\section{CONCLUSION}

As one conference participant put it "we should look to make new kinds of mistakes rather than repeat the mistakes of the past," as we seek to integrate the best that ITEM systems might have to offer with our research and development agendas for educational advancement and reform. In these agendas, the indications are that alternative and new approaches to curricula, learning and teaching are required. Information technology has already demonstrated itself to be a powerful tool for the enhancement of both curricula and learning and in the implementation of the desired alternative and new approaches. While much ingenuity has been shown in designing and using the ITEM systems demonstrated at this conference, more ingenuity still is required to harness ITEM systems in support of the educational goals and objectives of the schools. Perhaps ITEM working conferences of the future might dedicate themselves to the achievement of this end. 